\title{
EFFECTS OF PENTOBARBITAL ON FIXED-RATIO REINFORCEMENT ${ }^{1,2}$
}

\author{
Marcus B. Waller ${ }^{3}$ and W. H. Morse
}

HARVARD MEDICAL SCHOOL

\begin{abstract}
Certain doses of pentobarbital consistently increased the rate of pecking engendered by a fixedratio schedule of 30 responses in a group of 13 pigeons, and still higher doses produced decrements in rate of responding. For individual subjects, the dose-effect functions were qualitatively similar, but differed with respect to the doses producing the maximum increase and subsequent decrease in rate. In general, the maximum occurred at lower doses and the decrement was greater at the highest dose in the birds with the highest control rates. It was also possible to distinguish between the effects of pentobarbital and several other drugs on the behavior maintained by FR 30. The results indicate that changes in rate of responding on FR 30 after drug administration are dose-dependent, drug-specific effects.
\end{abstract}

The report by Dews (1955) that responding of pigeons on a fixed-ratio schedule of $\mathbf{5 0}$ responses (FR 50) was reduced less than responding on a $15 \mathrm{~min}$ fixed-interval schedule (FI 15') by small doses of pentobarbital has been confirmed repeatedly using other barbiturates, other drugs, in other species, and with variations in the FR and FI schedule procedures (Aprison and Ferster 1961, Dews 1956, Hearst 1960, Herrnstein and Morse 1956, Verhave 1959). Since the major interest in these experiments was the dramatic difference between the effects of drugs on certain parameter values of FR and FI, little attention was given to the nature of the drug effects on FR. Indeed the results were considered to confirm the view that behavior maintained by FR is controlled so powerfully by the schedule itself that it is resistant to modification by other variables (Blough 1956, Dews 1956, Morse and Herrnstein 1956).

A more careful examination of the specific effects of changing environmental variables and of drugs on behavior maintained by FR does not indicate that insensitivity to change is a general property of behavior maintained by FR. While certain experimental operations, such as changing the level of deprivation (Ferster and Skinner 1957) and prefeeding (Dews 1956, Sidman and Stebbins 1954), do not affect the high steady rate following the pause after reinforcement on FR, sudden changes, such as the introduction of novel stimuli, may affect the steady running rate on FR (Ferster and Skinner 1957, pp. 77-83). In evaluating the modifibility of FR performances, the changes in responding following the presentation of a novel stimulus are surely as significant as the persistence of responding on FR when each response is severely punished (Azrin 1959).

Additional evidence that performances maintained by FR are modified in a graded manner by changes in experimental conditions comes from drug studies. All published reports showing numerical data on dose-effect functions on FR indicate that behavior on FR is modified in a continuously changing manner by increasing doses of drug (Dews 1955, Kelleher, Fry, Deegan, and Cook 1961, Owen 1960, Boren and Navarro 1959, Waller 1961). Even in the case of barbiturates, the small doses that do not reduce responding on FR do have an effect: they tend to increase the rate of responding. Interestingly, these rate increases on FR appear to be obtained more consistently after barbiturates (Dews 1955,

${ }^{1}$ This research was supported by grants from the U.S. Public Health Service (MY-2094, MF-12420, and SF-530) and the Eugene Higgins Trust.

${ }^{2}$ We wish to thank Mrs. Catherine Jackson, Mrs. Barbara Booth and Miss Olivia McKenna for assistance with these experiments. The drugs used in these studies were kindly given by the following companies: pentobarbital (Nembutal) by Abbott Laboratories; chlorpromazine (Thorazine) by Smith, Kline and French Laboratories; 5-(1, 3-dimethylbutyl) -5-ethyl barbituric acid by Eli Lilly and Company, and methamphetamine (Methedrine) by Burroughs Wellcome and Company.

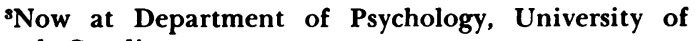
North Carolina. 


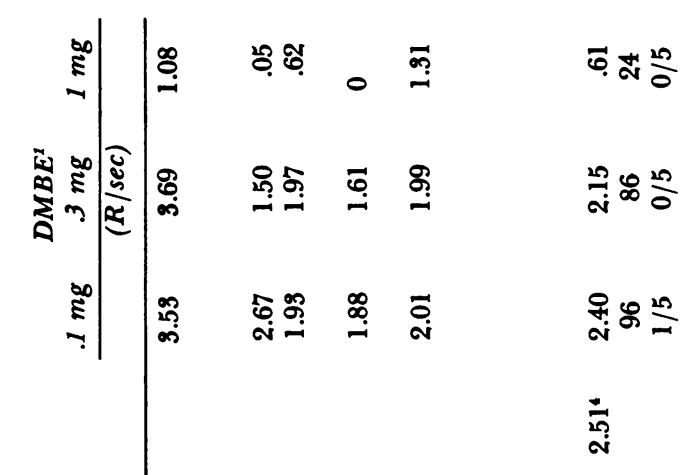

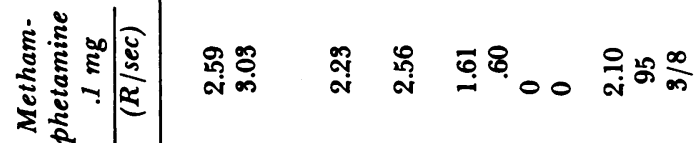

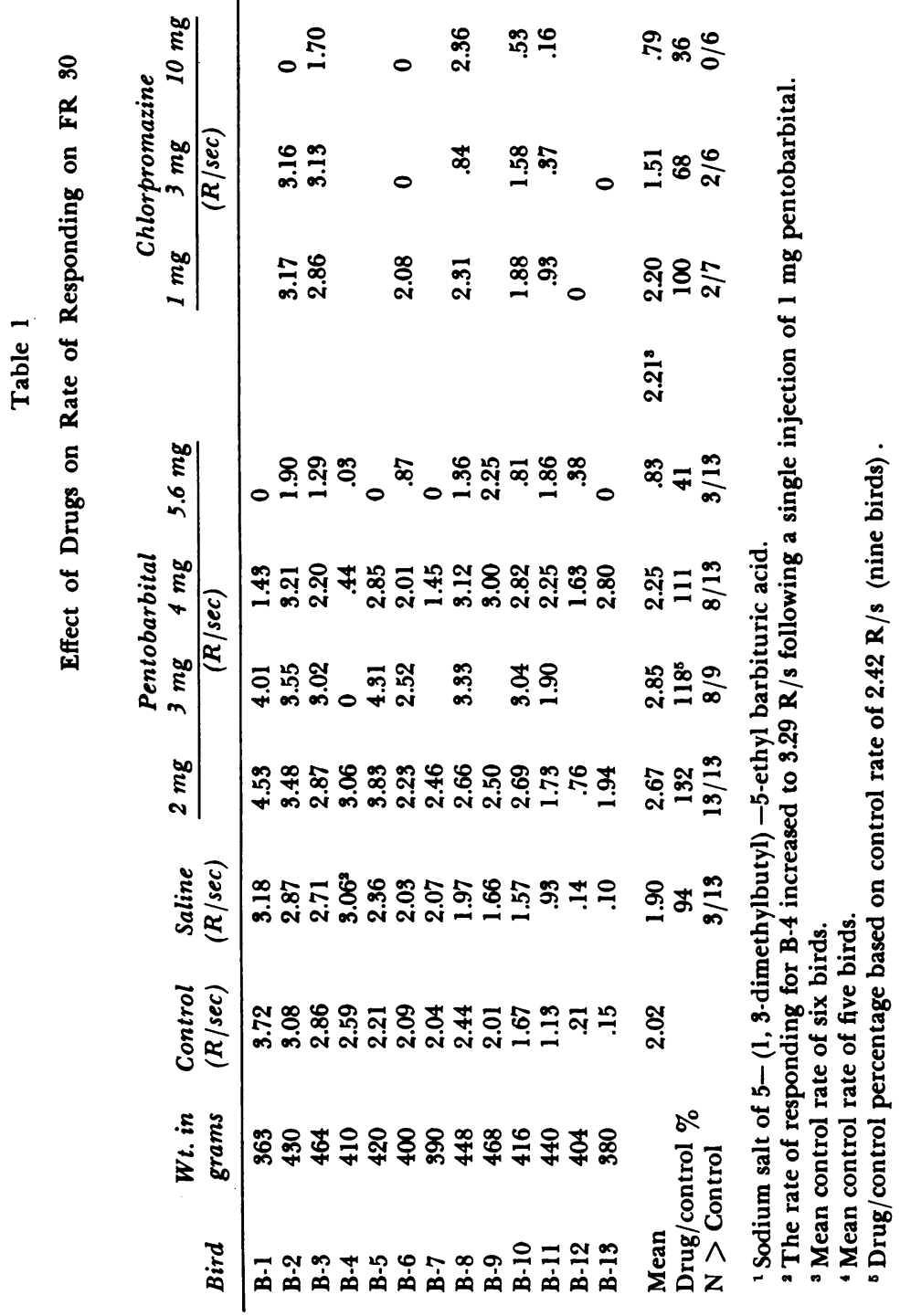


Kelleher et al. 1961) than after amphetamines (Kelleher et al. 1961, Owen 1960). Increased rates of responding on FR 60 in pigeons after chronic administration of bromide have been reported in studies by Ferster and Skinner (1957).

The present experiment was concerned with the effects of drugs on behavior maintained by FR 30. Dose-effect functions for pentobarbital were determined on a large number of subjects (13) having different previous experimental histories, and showing a wide range of rates of responding on the same FR 30 schedule. Observations were made on three other drugs, chlorpromazine, methamphetamine, and a barbiturate with convulsant properties (Swanson 1934, Knoefel 1945), to see if their effects could be distinguished from those of pentobarbital on behavior maintained by FR 30.

\section{METHOD}

\section{Subjects}

Thirteen male white Carneaux pigeons previously trained on several different schedules of intermittent reinforcement were used. All had served either in demonstration experiments on the effects of drugs on behavior, or in a student laboratory exercise in behavioral pharmacology (Dews and Morse 1958). Prior to this experiment all birds had received drug injections and had histories of responding on a FR 30 schedule when a blue light illuminated the response key. An effort was made to select birds which had different rates of responding on the FR 30 schedule.

\section{Apparatus}

An experimental chamber was connected to control and recording equipment in an adjacent room. The chamber, similar to that used by Ferster and Skinner (1957), has been described elsewhere (Dews and Morse 1958). A standard response key, 1 inch in diameter, was mounted on one wall of the chamber approximately 3 in. above a 2 in. square opening through which the pigeon was occasionally given access to grain for $3 \mathrm{sec}$. A "feedback relay" within the chamber provided a discrete click stimulus each time the response key was operated. Continuously present white noise masked most extraneous sounds.

\section{Procedure}

For $15 \mathrm{~min}$ after a pigeon was placed in the experimental chamber all lights in the chamber were out. Responses during this period were recorded and operated the feedback relay, but had no other effects. After $15 \mathrm{~min}$ a 10-min experimental period began, during which the chamber was illuminated by a 25 watt bulb and the key was transilluminated by two 6 -watt blue lights. In the presence of the blue lights, each thirtieth peck on the key produced a 3-sec presentation of the food tray. During the food presentation the key light was extinguished and responses were recorded on a separate counter. The blue light appeared again at the end of the food presentation, and the thirtieth peck was reinforced. An elapsed time meter recorded the time during which the key light was on. Average rates of responding were determined by dividing the total number of responses occurring when the key was lighted by the total time the key was lighted. All results are reported as averaged responses per second $(R / s)$.

Pentobarbital sodium was dissolved in $0.9 \%$ sodium chloride solution and injected intramuscularly immediately before the subject was put into the experimental chamber. The effects were therefore measured between 15 and $25 \mathrm{~min}$ after the drug was injected. The volume of solution was $0.5 \mathrm{ml}$ or less. Chlorpromazine hydrochloride, methamphetamine hydrochloride, and the sodium salt of 5(1, 3-dimethylbutyl)-5-ethyl barbituric acid (DMBE) were given in the same way. The doses specified are the total doses of these salts given to the birds.

\section{RESULTS}

The results of all drug experiments are summarized in Table 1. The rates reported for the control condition are based on an average of six to eight observations after the subject had reached a stable level of performance. The saline observations usually represent the mean of two determinations. The pentobarbital observations are means of at least two observations. The other drug points are based on single determinations at each dose level. The mean rate of responding, the ratio of rate after drug to control rate, and the number of subjects having a rate after 
drug greater than the control value $(\mathrm{N}>\mathrm{C})$ are shown for each dose in the last three rows of the table.

Pentobarbital was able to increase the rates of responding of all subjects. The increase was least for B-3 (an increase of .18 R/s after $3 \mathrm{mg}$ ) and greatest for B-5, B-11, and B-13 (increases of over $2 \mathrm{R} / \mathrm{s}$ ). The average increase was greatest after $2 \mathrm{mg}$, which raised the average rate $32 \%$ above the control level to $2.67 \mathrm{R} / \mathrm{s}$. The average rate after $5.6 \mathrm{mg}$ was well below the control level, so over a threefold range, pentobarbital produced both increases and decreases in rate of responding.

The summary ( $N>$ control) shows that, whereas $0.5 \mathrm{ml}$ saline reduced response output below the control level in 10 of 13 animals, $2 \mathrm{mg}$ pentobarbital increased the rate of responding in 12 of the 13 birds. Eight of the nine birds given $3 \mathrm{mg}$ pentobarbital also showed an increase in rate. Following the $4 \mathrm{mg}$ dose eight of the 13 birds showed increased rates and following the $5.6 \mathrm{mg}$ dose three of the birds still had rates above control values, but lower than after $4 \mathrm{mg}$.

The drugs other than pentobarbital did not as consistently increase rates of responding. Chlorpromazine increased the rate in three of the six birds studied and $0.1 \mathrm{mg}$ methamphetamine increased the rate in three of the eight birds given this single dose. The rate increased above the control level in only one of five birds given DMBE and this value did not exceed the increase which saline also produced. None of these drugs increased the mean rate above the control level at any dose.

The data for pentobarbital from Table 1 are plotted in Fig. 1 and 2 as dose-effect functions for individual birds. All 13 doseeffect curves are qualitatively similar in that the lowest dose of pentobarbital usually increased the rate of responding. Higher doses may increase the rate still more, up to a maximum, above which increasing doses cause decrements in rate. Figures 1 and 2 show certain differences between the subjects. The birds shown in Fig. 1 had the common characteristic that the rate of responding following $2 \mathrm{mg}$ was greater than the rate following $4 \mathrm{mg}$ and conversely, the birds shown in Fig. 2 showed a higher rate after $4 \mathrm{mg}$ than after $2 \mathrm{mg}$. Also, the control rates of responding were higher for the birds in Fig. 1 than for the birds in Fig. 2. With the exception of B-8 and

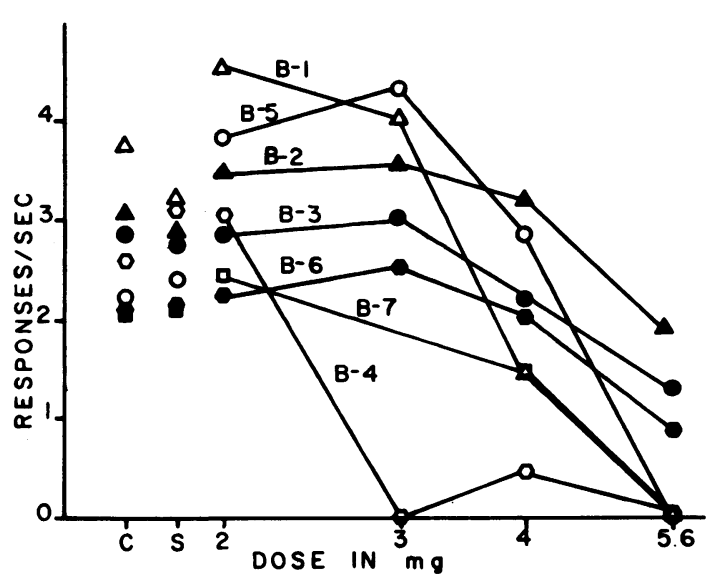

Fig. 1. Effects of pentobarbital (Log Scale) on rate of responding on FR 30. Dose-effect curves are shown for seven birds individually.

B-9, all birds in Fig. 1 had control rates above $2 \mathrm{R} / \mathrm{s}$ and all birds in Fig. 2 had rates below $2 \mathrm{R} / \mathrm{s}$. In general then, the birds shown in Fig. 1 had higher control rates, showed the maximum increase at lower doses and were more depressed by the highest dose than the birds graphed in Fig. 2. In fact three of the birds shown in Fig. 2 still had rates above their control value after $5.6 \mathrm{mg}$ pentobarbital.

Still other factors besides control rate partly determine the effects of pentobarbital on FR 30. The weight of the bird appears to have made a difference at the $5.6 \mathrm{mg}$ dose. The five birds which had rates above $1 \mathrm{R} / \mathrm{s}$ after $5.6 \mathrm{mg}$ all had weights greater than $425 \mathrm{~g}$; three of the birds that did not respond after $5.6 \mathrm{mg}$ had weights below $400 \mathrm{~g}$. Still another factor which seemed to have some relation to the observed effect of pentobarbital was the

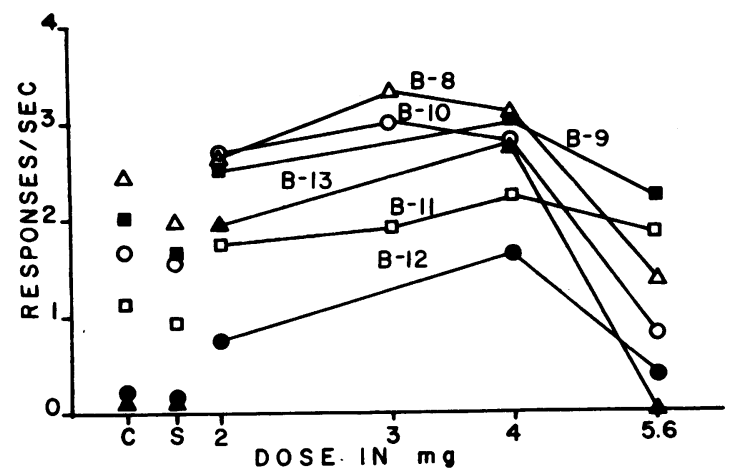

Fig. 2. Effects of pentobarbital (Log Scale) on rate of responding on FR 30. Dose-effect curves are shown for six birds individually. 
past schedule of drug injections for the birds. Seven of the eight birds that responded after the $5.6 \mathrm{mg}$ dose had extensive previous history of pentobarbital injections; of the five birds that did not respond only two had received frequent injections of pentobarbital.

Figure 3 shows sample cumulative records for two drug and control sessions for two birds. For each bird the dose shown gave the maximum increase. It is clear that the reproducibility of the effects of pentobarbital is quite high under these conditions.

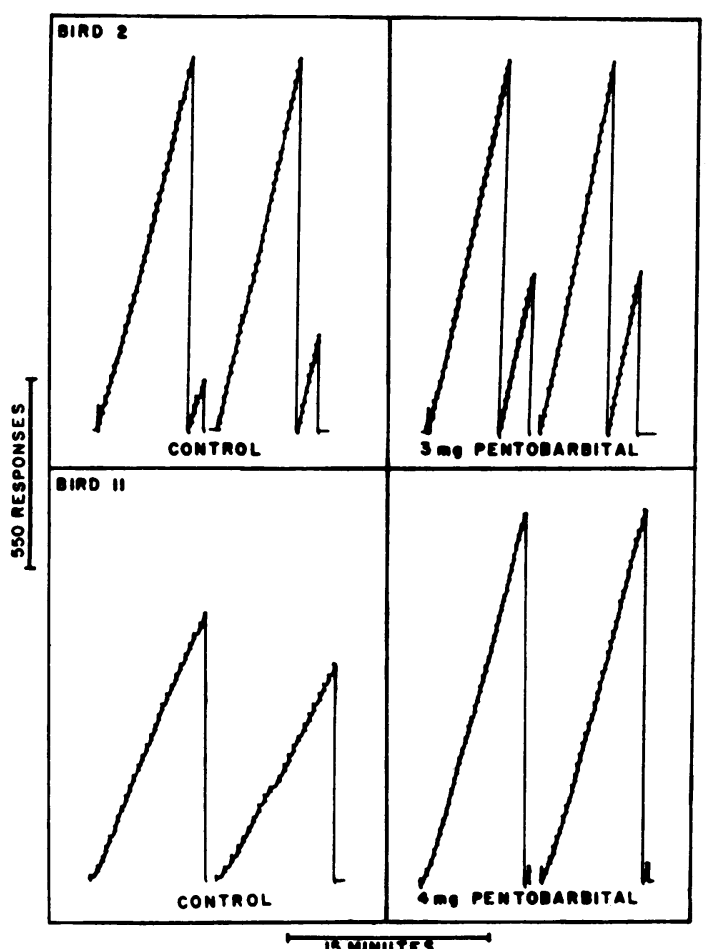

Fig. 3. Cumulative-response records for B-2 and B-11 on two control and two drug days. The number of responses emitted on the two control days differ for B-2 by 132 responses and for $B-11$ by 150 responses. The number of responses emitted on the two drug days differ by only 28 responses for B-2 and nine responses for B-11. The total number of responses on the drug days increased about 200 responses for B-2 and about 400 responses for $B-11$.

\section{DISCUSSION}

The present findings show unequivocally that small doses of pentobarbital in the range that produce decrements in responding on 5 to $15 \mathrm{~min}$ FI schedules consistently increase the rate of responding of pigeons maintained on a FR 30 schedule of food reinforcement. The findings agree closely with the results reported by Dews (1955) for pentobarbital in the pigeon, and those in rats on FR 50 after phenobarbital reported by Kelleher, et al. (1961). Not only does responding maintained by FR 30 show systematic changes with increasing doses of pentobarbital, but also it was less consistently increased by the other drugs used. It is interesting that DMBE, a barbiturate with convulsant properties (Swanson 1934, Knoefel 1945) did not produce rate increases.

Pentobarbital appeared to have qualitatively similar effects on behavior maintained by FR 30 even though the average rate of responding varied widely from subject to subject. In the present experiments, the control rates ranged from a low of $0.15 \mathrm{R} / \mathrm{s}$ for $\mathrm{B}-13$ to a high of $3.72 \mathrm{R} / \mathrm{s}$ for B-1. A comparison of the data shown in Fig. 1 and 2 indicates that birds with low control rates have higher rates after the $4 \mathrm{mg}$ dose, and are less depressed after the $5.6 \mathrm{mg}$ dose than are birds with high control rates. Previously, dependencies of drug effect upon rate have been noted for amphetamines (Dews 1958a, Dews 1958b, Kelleher et al. 1961) and chlorpromazine (Morse 1960), and it seems likely that barbiturates show such dependencies too. It is not clear at present which of the factors determining the control rate is most responsible for the drug effect, and research is now in progress to analyze the behavior maintained by FR reinforcement in greater detail, and to relate the effects of drugs to these characteristic features of FR.

It should be pointed out, however, that the existence of an already high rate does not in itself prohibit an increase in rate following a drug. When rates are already high it is tempting to suppose the further increases in rate are constrained by a "rate ceiling" or physiological limit. In this experiment the fact that B-1 increased its control rate from $3.72 \mathrm{R} / \mathrm{s}$ to $4.53 \mathrm{R} / \mathrm{s}$ after $3 \mathrm{mg}$ pentobarbital makes any argument that the rates reported are constrained by a physiological limit untenable for the other 12 birds.

Although all the birds in this experiment displayed the characteristic FR pattern of responding (a pause after reinforcement followed by an abrupt change to a fairly steady rate), several of them had average rates lower than those reported by Ferster and Skinner 
(1957, p. 48) for small-valued FR schedules (particularly B-10, B-11, B-12, and B-13). After pentobarbital, the rates of responding increased appreciably for all these birds, and subsequently returned to the lower control rate. The demonstrated capability of these subjects to respond at high rates under some conditions rules out the possibility that their low rates on FR 30 were due to a lack of the differentiated peck topographies necessary to produce high rates. Rather, it suggests that the control rates for each bird were due to the dynamic balance of the influences operating in the present experiment.

A final comment on the "insensitivity to drugs" of FR performances seems appropriate. The finding that FR performances are less suppressed by small doses of certain drugs than other schedule performances is clearly established. There has been some tendency, however, to regard this differential sensitivity simply as a reflection of general resistance to change of behavior on FR. Behavior on FR has been considered as a control for nonspecific gross effects of drugs, but the absence of gross reduction in responding on FR is not an inevitable result that follows from the stable patterns of responding engendered by FR. The present result, and also previous quantitative investigations of $F R$, indicates that the absence of gross disruption of behavior on FR to drug is a drug-specific effect. Certain drugs, such as scopolamine (Boren and Navarro 1959) and chronically administered chlorpromazine (Waller 1961) appear to affect FR and FI components of a multiple schedule at comparable doses. The demonstration that moderate doses of pentobarbital have a consistent rate-enhancing effect on FR 30 supports the concept of differential sensitivity of schedule-controlled performance to drugs, but it does not support the notion that FR performances are resistant to modification by drugs.

\section{REFERENCES}

Aprison, M. H., and Ferster, C. B. Neurochemical correlates of behavior. 1. Quantitative measurements of the behavioral effects of the seratonin precursor, 5hydroxytryptophan. J. Pharmacol. exp. Ther., 1961, 131, 100-107.

Azrin, N. H. Punishment and recovery during fixedratio performance. J. exp. Anal. Behav., 1959, 2, 301-305.
Blough, Donald S. Technique for studying the effects of drugs on discrimination in the pigeon. Ann. N.Y. Acad. Sci., 1956, 65, 334-344.

Boren, John J. and Navarro, Albert P. The action of atropine, benactyzine, and scopolamine upon fixedinterval and fixed-ratio behavior. J. exp. Anal. Behav., 1959, 2, 107-115.

Dews, P. B. Studies on behavior. I Differential sensitivity to pentobarbital of pecking performance in pigeons depending on the schedule of reward. $J$. Pharmacol. exp. Ther., 1955, 113, 393-401.

Dews, P. B. Modification by drugs of performance on simple schedules of positive reinforcement. Ann N.Y. Acad. Sci., 1956, 65, 268-281.

Dews, P. B. Analysis of effects of psychopharmacological agents in behavioral terms. Federation Proc., 1958, 17, 1024-1030. (a)

Dews, P. B. Studies on behavior. IV Stimulant actions of methamphetamine. J. Pharmacol. exp. Ther., 1958, 122, 137-147. (b)

Dews, P. B. and Morse, W. H. A psychopharmacology exercise for medical students. J. med. Educ., 1958, 33, 726-730.

Ferster, C. B. and Skinner, B. F. Schedules of Reinforcement. New York: Appleton-Century-Crofts, 1957.

Hearst, Eliot. Multiple schedules of time-correlated reinforcement. J. exp. Anal. Behav., 1960, 3, 49-62.

Herrnstein, R. J. and Morse, W. H. Selective action of pentobarbital on component behaviors of a reinforcement schedule. Science, 1956, 124, 367-368.

Kelleher, Roger T.; Fry, William; Deegan, John; and Cook, Leonard. Effects of meprobamate on operant behavior in rats. J. Pharmacol. exp. Ther., 1961, 133, 271-280.

Knoefel, P. K. Stimulation and depression of the central nervous system by derivatives of barbituric and thiobarbituric acids. J. Pharmacol. exp. Ther., 1945, 84, 26-33.

Morse, W. H. Some factors determining the behavioral effect of chlorpromazine. The Pharmacologist, 1960, 2, 71 .

Morse, W. H. and Herrnstein, R. J. Effects of drugs on characteristics of behavior maintained by complex schedules of intermittent positive reinforcement. Ann. N.Y. Acad. Sci., 1956, 65, 303-317.

Owen, John E. Jr. The influence of $d l-, d$, , and $l$ amphetamine and $d$-methamphetamine on a fixedratio schedule. J. exp. Anal. Behav., 1960, 3, 293-310.

Sidman, Murray, and Stebbins, William C. Satiation effects under fixed-ratio schedule of reinforcement. J. comp. physiol. Psychol., 1954, 47, 114-116.

Swanson, E. E. Short acting barbituric acid derivatives. Proc. Soc. Exp. Biol. Med., 1934, 31, 963-964.

Verhave, Thom. The effects of secobarbital on a multiple schedule in the monkey. J. exp. Anal. Behav., 1959, 2, 117-120.

Waller, Marcus B. Effects of chronically administered chlorpromazine on multiple-schedule performance. J. exp. Anal. Behav., 1961, 4, 351-359.

Received March 23, 1962 